\title{
Pour en lire plus : Perspectives globales sur la spiritualité et l'éducation.
}

\section{Virginie Boelen}

\section{(2) OpenEdition Journals \\ Édition électronique \\ URL : https://journals.openedition.org/ere/6183 \\ DOI : $10.4000 /$ ere.6183 \\ ISSN : 2561-2271 \\ Éditeur}

Centr'ERE

Référence électronique

Virginie Boelen, «Pour en lire plus : Perspectives globales sur la spiritualité et l'éducation. », Éducation relative à l'environnement [En ligne], Volume 16 - 1 | 2021, mis en ligne le 10 mars 2021, consulté le 28 mai 2021. URL : http://journals.openedition.org/ere/6183; DOI : https://doi.org/10.4000/ere.6183 


\title{
Pour en lire plus : Perspectives globales sur la spiritualité et l'éducation.
}

\author{
Virginie Boelen
}

\section{RÉFÉRENCE}

Watson, J., de Souza, M. et Trousdale, A. (dir.). (2014). Global perspectives on spirituality and education. New York and London : Routledge. 313 pages 


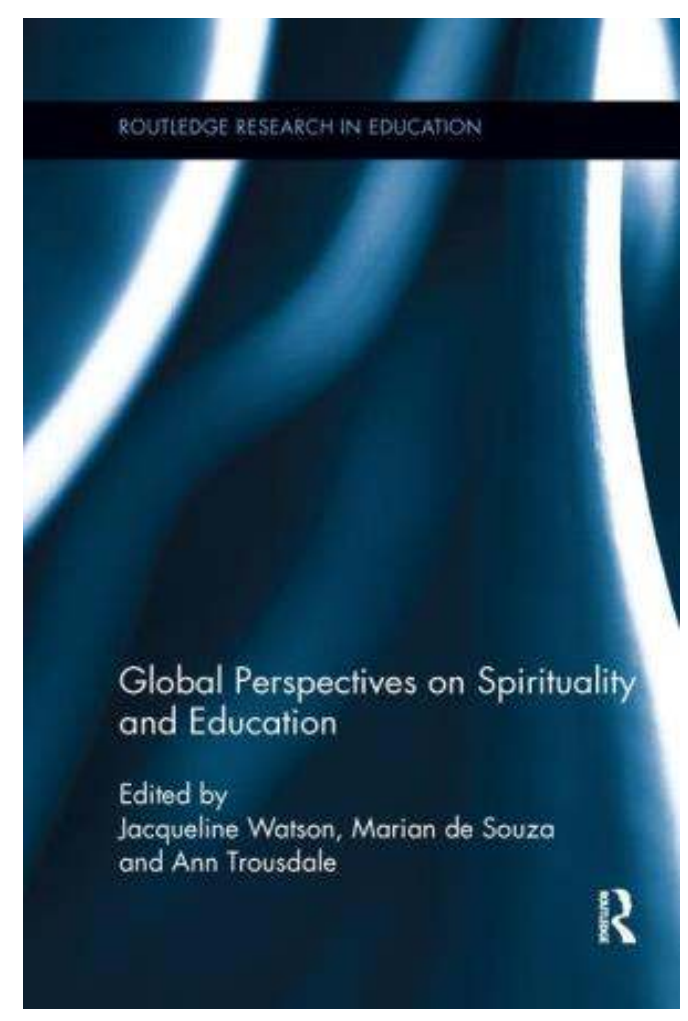

1 Cet ouvrage de 22 chapitres explore les relations entre la spiritualité et l'éducation dans différentes régions du monde : l'Europe majoritairement anglophone et Israël, la région Australasienne et enfin, les Amériques. Le dernier chapitre permet d'appréhender quelques thèmes clés et récurrents tels que le concept de spiritualité, son rapport au religieux en éducation, la place de la spiritualité dans les curriculums et le rôle de l'enseignant.

2 Le premier constat que font les auteurs est que la perception de la spiritualité ne peut être comprise en dehors des contextes sociaux, historiques, politiques et culturels. Ainsi, en Europe, la religion judéo-chrétienne a prédominé à travers l'histoire et l'éducation religieuse fait encore partie de certaines institutions (comme en Belgique ou à Malte) où la dimension spirituelle est prise en compte. C'est également le cas d'Israël et du Brésil.

3 Si aujourd'hui encore, peu s'entendent sur une définition claire et unanime du spirituel, celui-ci concerne - de façon consensuelle - des valeurs fondamentales de relation à l'autre. Comme le souligne Ron Best, «faciliter le développement de sa capacité à vivre certaines expériences qui nous font sentir pleinement humains, vivants et en connexion avec l'autre tel que le fait d'aimer et se sentir aimé, sont de toute évidence des enjeux fondamentaux en éducation » (traduction libre, p. 16).

4 Pour l'ensemble des auteurs, une telle prise en compte en éducation conduit au bienêtre et au développement d'une citoyenneté axée sur des valeurs d'empathie, d'inclusion et d'attention à l'autre de façon responsable pour l'ensemble de la société. Ceci s'applique d'autant plus que les sociétés deviennent significativement multiculturelles, multiethniques et multiconfessionnelles. Il est alors question de spiritualité humaniste selon Ron Best ou encore de spiritualité civique selon Michael Dallaire. Kate Adams et Adrian-Maro Gillel soulignent l'importance du développement spirituel de l'enfant en éducation tel que reconnue par la Convention des Nations Unies 
concernant les droits de l'enfant (2001) ainsi que dans le rapport Delors de l'Unesco (1996).

5 Dans certains pays de culture judéo-chrétienne tels qu'en Angleterre, en Irlande, en Australie et au Québec, il est question d'une éducation publique séculière, où le développement spirituel s'est dissocié de toute éducation religieuse et fait partie du curriculum scolaire pour être traité de façon transversale. James O'Higgins et Caroline Renehan, ainsi que Graham Rossiter identifient toutefois deux entraves majeures à la prise en compte de la spiritualité en éducation. D'une part, le fait que le spirituel est souvent assimilé au religieux. D'autre part, l'éducation instrumentale prédominante, qui entretient l'individualisme, la compétition et le consumérisme, représente une menace pour le développement spirituel qui, au contraire, favorise l'empathie, l'attention à l'autre et le bien commun selon un processus démocratique axé sur le dialogue. Pour Adrian-Mario Gellel, le curriculum utilitaire, avec la fragmentation du savoir, laisse peu de place à la nature holistique de la spiritualité.

6 La perception du spirituel est tout autre dans les pays d'Asie tels que le Bhoutan, la Thaïlande et le Japon non impactés par la colonisation judéo-chrétienne où la nature holistique de la spiritualité s'associe aux philosophies bouddhistes, taoïstes, confucianistes et shintoïstes et fait partie du quotidien selon un tout cohérant où on parle de pratiques spirituelles en éducation, telles que la méditation conduisant au bien-être. À cet effet, Noa Jones et Michael Ernest Jones constatent que le rapprochement vers une éducation occidentale caractérisée par les apprentissages cognitifs et la promotion d'une vie consumériste conduit à une mise à l'écart significative de toute spiritualité.

7 Le cas néo-zélandais développé par Deborah Fraser est atypique. Bien qu'étant un pays colonisé par le judéo-christianisme, la spiritualité a gardé sa nature holistique grâce à la forte présence de la culture indigène des Maoris. Depuis 1937, le développement spirituel fait partie du curriculum séculier dès la petite enfance, où le spirituel correspond à un sens profond de la connexion à la terre, associé à un sentiment d'appartenance et de responsabilité, source de bien-être.

8 De toute évidence, comme le soulignent plusieurs auteurs de cet ouvrage, le mandat de traiter de spiritualité en éducation est un défi pour les enseignants de notre monde occidental. Leur formation est fondamentale dans ce domaine où il est question d'approches misant sur des expériences à vivre combinées à des approches dialogiques, herméneutiques et démocratiques. La spiritualité se vit dans la résolution de problèmes, la collaboration au service de l'autre et de la communauté, l'exercice de la pensée critique, la contemplation de la bonté et de la beauté pour entrer en résonnance avec le monde. À cet effet, James O'Higgins et Caroline Renehan soulignent tout l'apport de la pensée Deweyenne alors que Dora Incontri rappelle celle de Freire où apprenants et enseignant sont partenaires dans l'apprentissage. Pour ce faire, les enseignants doivent avoir au préalable expérimenté eux-mêmes, dans leur propre vie, la sagesse d'une expérience spirituelle.

9 Enfin, Kirsi Tirri et Martin Ubani soulignent l'importance de la recherche pour développer des stratégies qui permettent d'intégrer la nature holistique de la spiritualité dans l'enseignement. Jacqueline Watson, Marian de Souza et Ann Trousdale concluent l'ouvrage en observant que nos sociétés ont besoin d'une éducation à la sagesse qui implique engagement et responsabilité et contribue à contrer la violence du monde pris en compte moderne porté par l'éducation occidentale elle-même. Les 
jeunes ne seraient alors plus considérés comme des récipients passifs d'un savoir déterminé à l'avance, mais comme des êtres avec un extraordinaire potentiel d'autodéveloppement, dotés d'une pensée réflexive et dialogique en quête de savoir.

À bien des égards, on remarquera des rapprochements entre les approches préconisées par les auteurs de cet ouvrage pour favoriser le développement spirituel en éducation et celles qui sont privilégiées en éducation relative à l'environnement, ne serait-ce que les approches qui misent sur la praxis (selon Dewey), le développement de la pensée critique, la collaboration, la résolution de problèmes et le développement de la pensée libre et démocratique (selon les principes de Freire). Il faut noter que plusieurs chapitres de l'ouvrage collectif (Dallaire, Fraser, Nakagawa) soulignent le fait que le spirituel est la manifestation de la prise de conscience de la reliance à la nature et au monde qui nous entoure. L'environnement a donc une place importante dans le développement d'une relation d'ordre spirituel avec des approches telles que les récits, la méditation et l'art, qui sont propres aux cultures non impactées par la culture occidentale judéo-chrétienne. Le cas de la Nouvelle-Zélande est particulièrement intéressant avec la prise en compte de la culture Maori garante du maintien de la spiritualité selon une perspective non religieuse en éducation, où celle-ci est intégrée dans la trame curriculaire, favorisant un rapport profond à la terre.

\section{AUTEUR}

\section{VIRGINIE BOELEN}

Virginie Boelen est candidate au doctorat en éducation à l'Université du Québec à Montréal. Elle s'intéresse au développement spirituel en éducation en lien avec le rapport avec la nature. Elle est fondatrice des ateliers L'Arbre de Vie, ateliers multidisciplinaires offerts depuis 2009, qui favorisent la reliance dans le rapport esthétique à la nature selon une approche holistique. 